\title{
Evaluation of Renal Venous Impedance, Pyelocalyectasis and Their Correlation during Pregnancy Using Doppler Ultrasound Examination: A Case Control Study
}

\author{
Sharma $\mathbf{P}^{1}$, Shrestha $\mathrm{B}^{2}$, Ansari $\mathrm{MA}^{3}, \operatorname{Singh} \mathrm{D}^{4}, \operatorname{Singh} \mathrm{BP}^{4}$ \\ ${ }^{1}$ Department of Radiology and Imaging, Manipal Teaching Hospital, Pokhara, ${ }^{2}$ Department \\ of Obstetrics and Gynaecology, Nepalgunj Medical College, Banke, ${ }^{3}$ Department of \\ Radiology and Imaging, TU Teaching Hospital, Kathmandu, ${ }^{4}$ Department of Radiology and \\ Imaging, Nepalgunj Medical College, Banke.
}

\begin{abstract}
Objective: The objective of our study was to evaluate venous impedance, pyelocalyectasis and their correlation during pregnancy using Doppler ultrasound examination. Materials and methods: Doppler studies of bilateral kidneys were done in 41 singleton pregnant ladies of second and third trimester of pregnancy and 35 healthy volunteers. None of the ladies had prior history of renal diseases or renal surgery in the past and were clinically asymptomatic. Pelvicalyceal system dilatation of both kidneys was graded based on the separation of sinus echo at mid polar region. Doppler sonography of the interlobar veins of both kidneys was performed at mid polar region and venous impedance index was calculated. Correlation between venous impedance index and hydronephrosis was done using SPSS (11) software.

Results: The venous waveforms in pregnant women showed diminished phasic oscillations. Venous impedance in case was $0.31 \pm 0.06$ on the right side and $0.35 \pm 0.09$ on the left side and in control group was $0.43 \pm 0.06$ and $0.40 \pm 0.05$ on the right and left respectively. Difference between case and control was statistically significant $(\mathrm{p}<0.001)$. During second trimester venous impedance index was $0.34 \pm 0.06$ and $0.35 \pm 0.07$ on right and left side respectively. In the third trimester it was $0.31 \pm 0.05$ on the right side and $0.34 \pm 0.10$ on the left side. There was negative correlation between venous impedance and grade of hydronephrosis or gestational age. Conclusion: Venous impedance index was significantly lower in pregnant ladies than in control and there was a negative correlation between grades of hydronephrosis and venous impedance index.
\end{abstract}

Keywords: Hydronephrosis, Pregnancy, Venous Impedance index

\section{Introduction}

The anatomical, physiological, and biochemical changes in pregnancy are profound. Many of these changes begin

Correspondence to: Dr. Prakash Sharma

Department of Radiology and Imaging, Manipal Teaching Hospital, Pokhara, Nepal E-mail: prakashshrm@yahoo.com soon after fertilization and continue throughout gestation, and most of these remarkable adaptations occur in response to physiological stimuli provided by the fetus. Equally surprising is that the woman who was pregnant is returned almost completely to her pre-pregnancy state after delivery and lactation. The understanding of these adaptations to pregnancy is important.

A remarkable number of changes are 
observed in the urinary system as a result of pregnancy. Hydronephrosis and hydroureter is a frequent finding. It is due to ureteral compression and due to effect of progesterone. Ureteral dilatation is greater on the right side. ${ }^{1}$

Sonography remains a commonly used modality in the initial evaluation and diagnosis of renal obstruction. Doppler sonography has been used for obtaining more functional information in cases of hydronephrosis. In the acute phase of renal obstruction, pressure within the collecting system increases substantially, and a reduction in compliance of the renal vessels would be expected to develop rapidly. As a result of this, an increase in vascular resistance is observed. ${ }^{2,3}$

It has been suggested that the venous impedance index is more sensitive in detecting physiologic changes and can be useful in the evaluation of renal parenchymal compliance. ${ }^{3}$ Reduced compliance in acute renal obstruction results in dampening of these renal venous signals, and intraparenchymal venous flow is affected to a greater degree than the arterial flow. ${ }^{3}$

Study has shown that venous impedance in pregnant ladies is less than control group. ${ }^{4}$ No such study has been conducted in our region. This study was conducted to see the reproducibility of the observations in our part.

\section{Material and methods}

This prospective study was done between 25th January 2009 and 24th April 2009 at the department of Radiology and Imaging, Nepalgunj Medical College, Banke. Forty eight pregnant ladies between 18 and 35 years in second and third trimester of pregnancy undergoing obstetric scan were included in the study. These ladies had no prior history of loin pain, any renal disease, renal surgery or calculus. Ladies with prior history of renal disease, having single kidney, multifoetal pregnancy or with suspicion of any renal pathology were excluded from our study. Similarly, 35 healthy female volunteers between 18 and 35 years were taken as control. B mode and venous duplex study of bilateral kidneys were done in lateral decubitus position. Examination was done in GE Vivid 3 and Shimadzu 2200 pro machine. Informed consent was obtained from each patient in our study, and the protocol conformed to the ethics committee guidelines.

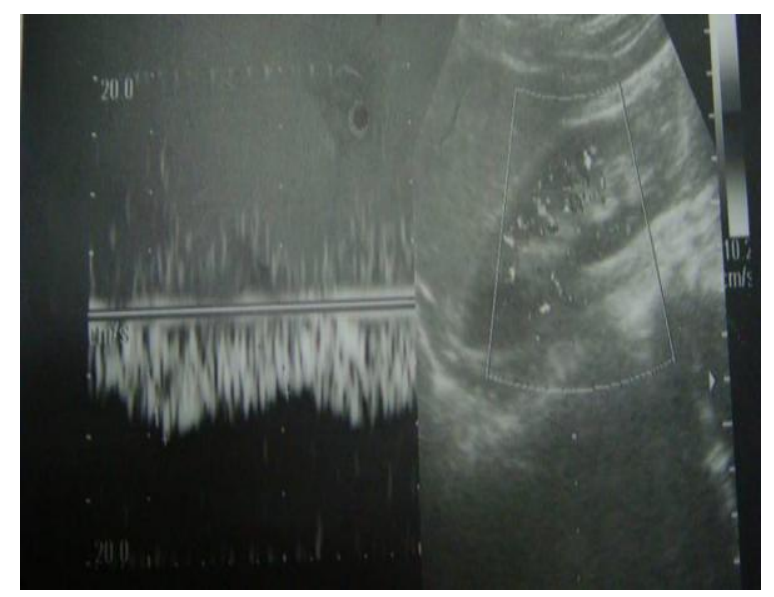

Fig 1: Venous Doppler of right kidney in control group showing normal phasic oscillation.

Patients were asked to void urine before starting the ultrasound examination. Pelvicalyceal system dilatation was graded from 0 to 3 indicating no pelvicalyceal dilatation $(\leq 5 \mathrm{~mm})$, mild $(6-10 \mathrm{~mm})$, moderate (11-15) and severe $(>15 \mathrm{~mm})$ pelvicalyceal dilatation, respectively based on the separation of sinus echo. ${ }^{5}$ Doppler sonography of the interlobar veins of both kidneys was performed at mid polar region with the peak flow signal as well as the impedance indexes noted. The venous impedance index was calculated as the value of the difference between the peak flow signal and the least diastolic flow signal divided by the peak flow value. ${ }^{3}$ Among the 48 pregnant ladies examined, we excluded four due to renal stone, two due to multifoetal pregnancy and one due to vesico- 


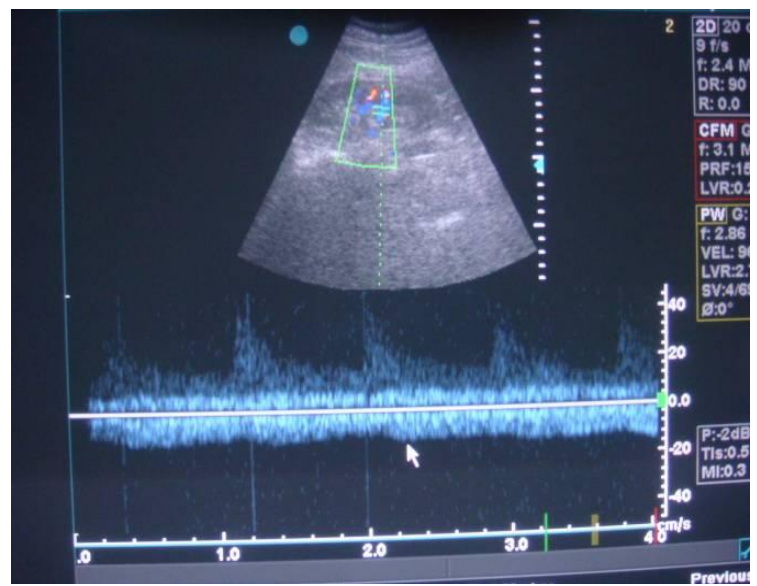

Fig 2: Venous Doppler study of left kidney in a pregnant lady with diminished phasic oscillation which is due to elevated presystolic flow. Arrow is pointing the peak venous flow.

ureteric junction stone. Remaining 41 were included for statistical analysis.

Statistical analysis was done using SPSS (11). The mean and standard deviations were calculated for each of the variables measured, paired student $t$ test was applied to find the differences between the venous impedance of right and left kidney in both case and control groups. The venous impedance of both kidneys in case was compared with the control group and the significance of the result was tested with a student $t$ test. Correlation between grades of hydronephrosis and venous impedance was done using Pearson Correlation. Similarly, Mann-Whitney U test was used to see the significance between gestational age and venous impedance. $P$ value of $<0.05$ was considered statistically significant.

\section{Result}

A total of 41 singleton pregnant ladies and 35 healthy female volunteers were included in our study. Mean age of the case group was $23.0 \pm 3.9$ years and that of the control group was $26.1 \pm 5.2$ years. Out of 41 pregnant ladies, 24 were in the second trimester of pregnancy (13-26 weeks) and 17 were in the third trimester of pregnancy (27-40 weeks).
Twenty three $(56 \%)$ pregnant ladies had no pelvicalyceal dilatation. Similarly, 13(32\%) and $5(12 \%)$ had mild and moderate hydronephrosis respectively on the right side. It was slightly less on the left side. $30(74 \%)$ had no hydronephrosis on the left side. 10(24\%) and 1(2\%) had mild and moderate hydronephrosis respectively on the same side.

Severe hydronephrosis was not seen on either side. None of the healthy volunteers in control group had hydronephrosis.

Venous impedance in case was $0.31 \pm 0.06$ on the right side and $0.35 \pm 0.09$ on the left side and in control group was $0.43 \pm 0.06$ and $0.40 \pm 0.05$ on the right and left side respectively. Difference between case and control was statistically significant ( $\mathrm{p}<$ 0.001). Lower impedance on left side in control was also statistically significant (0.04) (Table 1).

Table 1: Venous impedance index in case and control group

\begin{tabular}{|l|l|c|c|}
\hline & Case & Control & P Value \\
\hline $\begin{array}{l}\text { Right } \\
\text { Venous } \\
\text { Impedance }\end{array}$ & $0.31 \pm 0.06$ & $0.43 \pm 0.06$ & $<\mathbf{0 . 0 0 1 *}$ \\
\hline $\begin{array}{l}\text { Left } \\
\text { Venous } \\
\text { impedance }\end{array}$ & $0.35 \pm 0.09$ & $0.40 \pm 0.05$ & $\mathbf{0 . 0 0 1 *}$ \\
\hline $\begin{array}{l}\text { P value } \\
\text { * }\end{array}$ & $\mathbf{0 . 0 3 *}$ & $\mathbf{0 . 0 4 6 *}$ & \\
\hline Statistically significant & & \\
\hline
\end{tabular}

Venous impedance index was found to be decreased with the increasing gestational age. This was statistically significant on the right side $(\mathrm{p}=0.01)$ but insignificant on the left side (p 0.29) (Table 2).

Similarly, there was a negative correlation between the grades of hydronephrosis and venous impedance index $(\mathrm{r}=-0.68, \mathrm{p}<0.001$ for the right kidney and $\mathrm{r}=-0.33, \mathrm{p}=0.033$ for the left kidney) (Table 3) 
Impedance index was significantly lower in pregnant ladies even with no hydronephrosis than in control groups ( $p$ value $<0.001$ for right kidney and $\mathrm{p}=0.02$ for left kidney).

Table 2: Venous impedance index according to gestational age

\begin{tabular}{|l|l|l|}
\hline Gestational age & \multicolumn{2}{|c|}{$\begin{array}{l}\text { Venous Impedance } \\
\text { index }\end{array}$} \\
\cline { 2 - 3 } & Right & Left \\
\hline $\begin{array}{l}\text { 14-26 weeks } \\
\text { (Second trimester) }\end{array}$ & $\mathbf{0 . 3 4 \pm 0 . 0}$ & $\mathbf{0 . 3 5} \pm \mathbf{0 . 0 7}$ \\
\hline $\begin{array}{l}\text { 27-40 weeks } \\
\text { (Third trimester) }\end{array}$ & $\mathbf{0 . 3 1} \pm \mathbf{0 . 0}$ & $\mathbf{0 . 3 4} \pm \mathbf{0 . 1 0}$ \\
\hline P value & $\mathbf{0 . 0 1 *}$ & $\mathbf{0 . 2 9}$ \\
\hline * Statistically significant & & \\
\hline
\end{tabular}

There was significant difference in venous index between two kidneys only in the third trimester $(\mathrm{p}<0.042)$.

\section{Discussion}

Pregnancy is associated with various physiological changes. Physiological hydronephrosis is one of them. Doppler studies can be used to obtain functional information in obstruction. The arterial resistive index (RI) measurements have poor sensitivity and specificity for the simultaneous increase in resistance and reduction in compliance. ${ }^{6,7}$ Recently, it has been suggested that the venous impedance index is a more sensitive measure of physiologic changes and it can be useful in the evaluation of renal parenchymal compliance in cases of obstruction. ${ }^{3}$ Studies have shown mean venous impedance index on the acutely obstructed side to be lower than the index on the unobstructed side. ${ }^{8}$ The study was aimed to see the changes in venous impedance index during second and third trimester of pregnancy. There is diminished phasic oscillation in venous waveform during pregnancy which is due to elevated pre-systolic flow.
The impedance index is determined by both resistance and compliance of a vessel. Because normal venous resistance is negligible, the impedance index is mainly related to compliance in veins. ${ }^{3}$ There is increase in blood volume and cardiac output along with reduced peripheral vascular resistance in pregnancy. Reduction in venous impedance during pregnancy is due to reduced vascular compliance from increased interstitial pressure subsequent to partial obstruction of ureters by the gravid uterus and by the effect of progesterone., ${ }^{5,9}$ The flow pattern in intrarenal veins is affected by renal parenchymal histology as well as cardiac physiology. In our study only intrarenal veins were evaluated, the effect of haemodynamic and cardiac changes altering the venous flow were not studied.

Table 3: Venous impedance according to grades of hydronephrosis

\begin{tabular}{|l|l|l|}
\hline $\begin{array}{l}\text { Pelvicalyceal } \\
\text { system } \\
\text { dilatation } \\
\text { (grades) }\end{array}$ & \multicolumn{2}{l|}{$\begin{array}{l}\text { Venous impedance } \\
\text { index }\end{array}$} \\
\hline Right & Left \\
\hline (No dilatation) & $0.350 \pm .05$ & $\mathbf{0 . 3 6} \pm \mathbf{0 . 0 5}$ \\
\hline 1 (Mild) & $0.28 \pm 0.03$ & $\mathbf{0 . 3 1} \pm \mathbf{0 . 1 8}$ \\
\hline 2 (Moderate) & $\mathbf{0 . 2 3} \pm \mathbf{0 . 0 4}$ & $\mathbf{0 . 2 1}$ \\
\hline
\end{tabular}

In our study hydronephrosis on the right kidney was more than on the left side which is similar to other studies. ${ }^{5,4}$ It is due to the dextrorotation of the uterus. Venous impedance in the right kidney was 0.31 and 0.36 in the left kidney in pregnant ladies. Similarly in control group it was 0.43 and 0.40 on the right and left side respectively. Bateman and Cuganesen ${ }^{3}$ found the mean impedance indexes of 0.45 and 0.43 for the right and left kidneys respectively in control patients. Similar results were obtained by Karabulut $\mathrm{N}$ et al. ${ }^{4}$

Gyselaers $\mathrm{W}$ et $\mathrm{al}^{10}$ found that interlobar venous flow is different between left and 
right kidney only in the third trimester of pregnancy which is similar to our study. This difference is inversely related to pelvicalyceal dilatation, which may be explained by pelvic compression from the gravid uterus.

Differences between venous impedance in case and control group was statistically significant.

There was negative correlation between venous impedance and grade of hydronephrosis which was similar to other study ${ }^{4}$, while even pregnant ladies without hydronephrosis had significantly lower venous impedance values than control group. Therefore, not only ureteral obstruction by gravid uterus but also other factors such as hormonal effect might be involved in diminished venous impedance and dilated pelvocaliceal system.

In this study, the decrease in venous impedance index with increasing gestational age is in agreement with Karabulut $\mathrm{N}$ et al. ${ }^{4}$ Roobottom et al ${ }^{11}$ reported decreased hepatic venous pulsatility during pregnancy, which became completely flat with increasing gestational age. They attributed this alteration to increased cardiac output coupled with the increase in portal velocity and the pressure effect of the enlarged gravid uterus.

Although all the ladies in our study were asymptomatic with no prior history of renal diseases or calculus, our study did not attempt to find out other pathological causes of hydronephrosis, which was the major drawback in the study. Other limitations include small sample size, convenient sampling and limited time period. Large scale studies have to be done so that standards for the renal venous Doppler during pregnancy can be set.

In conclusion, renal venous impedance index was found to be decreased in normal pregnancy than in control. There is a negative correlation between venous impedance index and grades of hydronephrosis.

\section{References}

1. Cunningham FG, Norman F, Gant NF , Kenneth J, Leveno KJ, Larry C et al. Physiology of pregnancy. In: Cunningham FG, Whitridge $\mathrm{J}$ eds. Williams Obstetrics, 21st edition: New York, McGraw-Hill Professional, 2001:61-142.

2. Miletic D, Fuckar Z, Sustic A, Mozetic V, Smokvina A, Stancic M. Resistance and pulsatility indices in acute renal obstruction. J Clin Ultrasound 1998; 26:79-84.

3. Bateman GA, Cuganesan R. Renal vein Doppler sonography of obstructive uropathy. Am J Roentgenol 2002; 178:921-925.

4. Karabulut N, Baki YA, Karabulut A. Renal vein Doppler ultrasound of maternal kidneys in normal second and third trimester pregnancy. $\mathrm{Br} \mathrm{J}$ Radiol 2003; 76:444-447.

5. Peake SL, Roxburgh HB, Langlois SL. Ultrasonic assessment of hydronephrosis of pregnancy. Radiology 1983; 146:167170 .

6. Mostbeck GH, Zontsich T, Turetschek $\mathrm{K}$. Ultrasound of the kidney: obstruction and medical diseases. Eur Radiol 2001; 11:1878-1889.

7. Pozniak MA, Kelcz F, Stratta RJ, Oberley TD. Extraneous factors affecting resistive index. Invest Radiol 1988; 23:899-904.

8. Oktar SO, Yucel C, Ozdemir H, Karaosmanoglu D. Doppler Sonography 
of Renal obstruction Value of Venous Impedance Index Measurements. J Ultrasound Med 2004; 23:929-936.

9. Rasmussen PE, Nielsen FR. Hydronephrosis during pregnancy: a literature survey. Eur J Obstet Gynecol Reprod Biol 1988; 27:249-259.

10. Gyselaers W, Verswijvel G, Molenberghs G, Ombelet W. Interlobar
Venous Flow Is Different between Left and Right Kidney in Uncomplicated Third Trimester Pregnancy. Gynecol Obstet Invest 2008; 65:6-11.

11. Roobottom CA, Hunter JD, Weston MJ, Dubbins PA. Hepatic venous Doppler waveforms: changes in pregnancy. J Clin Ultrasound 1995; 23:477-482. 